\title{
The Determination of Condition Met by Boom System Working in Safety Based on Multiple Load Case Analysis
}

\author{
Wenhui Yue*, Jianxin Weng, Liangpei Huang, Yongxing Zhu and Penghui Duan
}

\author{
Hunan University of Science and Technology, Hunan Provincial Key Laboratory of Health Maintenance for Mechanical \\ Equipment, Xiangtan, Hunan, 411201, China
}

\begin{abstract}
Loads subjected by the boom system on the concrete pump are so complex, that fatigue cracks or fatigue fractures appear, which may lead to loss of property and casualty. However, when the concrete pump is functioning in safe condition, the damage of the boom system is reduced, thereby preventing the accidents. In order to select safe working conditions, a boom system of $37 \mathrm{~m}$ concrete pump as research object should be adopted. The finite element analysis is carried out on the boom system based on MSC. Patran and Nastran, with regularly varying degrees, and changing trends of the maximum stresses subjected by booms with the change of degrees of booms, attained a safe condition of the boom system. Finally, taking the four kinds of typical foundation casting working conditions as example, the feasibility of using this condition to determine the safe working condition has been verified.
\end{abstract}

Keywords: Boom system, changing trends of the maximum stresses, finite element analysis, multiple load case, safety working condition.

\section{INTRODUCTION}

In the 21 st century, protecting the earth's environment, constructing circular economy, and maintaining social sustainable development have become a common topic of concern all over the world $[1,2]$. In this situation, the remanufacturing engineering has played a pivotal role. The concrete pump plays an important role in the economic construction as a key part of construction machinery. Due to huge weight, large materials consumption and serious environmental pollution, the concrete pump has to face pressures from resources and environmental friendly requirements to develop the technology of remanufacturing. When the truck mounted concrete pump usually works in a safe condition, under which the less stresses are subjected by the boom system, the damage reduced, improving the utilization of sections.

The concrete pumps have been widely used in modern construction [3], which are made up of chassis, pumping system and the boom system, and the booms are the key components of the boom system. In the process of pumping, the concrete pump subjects various loadings, and the booms are under the action of alternating stress, thereby causing fatigue cracks or fatigue fracture [4]. In order to avoid such accidents and achieve the selection of safe working conditions, according to the degrees of booms when the concrete pump is working, the booms of $37 \mathrm{~m}$ concrete pump are taken as research object. The finite element analysis is carried out on the booms under various working conditions

*Address correspondence to this author at the Hunan University of Science and Technology, Hunan Provincial Key Laboratory of Health Maintenance for Mechanical Equipment, Xiangtan, Hunan, 411201, China;

Tel: +8613507322253; E-mail: jwc1999178@126.com based on MSC. Patran and Nastran, and the changing trends of the maximum stresses subjected by each boom with the change of degrees of booms, helped attain safe working conditions of the boom system. Finally, taking the four kinds of typical foundation casting working conditions as example, the feasibility of using this condition to determine the safe working condition is verified.

\section{THE STRUCTURE OF BOOM SYSTEM}

The boom system consists of booms, connecting rods, cylinders and other components [5], as shown in Fig. (1). The serial numbers of $1,2,3,4$ and 5 refers to the turntable, boom 1 , boom 2 , boom 3 , boom 4 and boom 5 , respectively. The booms can be simplified to a slender cantilever beam, with the main subjective loading being dead weight, which is required to be of high strength, good rigidity and light weight. The structure of booms is generally designed as a box-beam welded by four steel plates, and the material of booms is alloy structural steel, which is of high strength and fine grain. To make full use of excellent mechanical properties of high strength steel, the structure of booms is designed into gradient beam, with the end of booms near the turntable being called big head. The other end is called the small head. The degrees between boom 1 and horizontal direction, boom 1 and boom 2, boom 2 and boom 3 and boom 3 and boom 4 are named as $\theta_{1}, \theta_{2}, \theta_{3}$ and $\theta_{4}$ respectively. When the concrete pump is working, the degrees between the booms content are: $0^{\circ}<\theta_{1}<90^{\circ}, 90^{\circ}<\theta_{2}<180^{\circ}, 90^{\circ}<\theta_{3}<180^{\circ}, 0^{\circ}<\theta_{4}<180^{\circ}$.

\section{SELECTION OF TYPICAL WORKING CONDITIONS}

The principle of selecting appropriate working conditions is as follows: adopt a single variable principle, through the rotation of one boom, change the degree between the boom and the next boom, keeping the other booms in one posture, 
which is selected at a certain level, given the boom system subjected to the largest stress when the working condition of boom system is under certain level [6]. When the other booms are in the worst condition, the changing degree can satisfy the condition of the boom system working with safety, thereby ensuring safety the boom system working in other conditions.

The first set of working conditions: boom 1 rotates around the hinge point between boom 1 and 2. According to the existing working conditions, as soon as and $\theta_{1}, \theta_{3}$ and $\theta_{4}$ equals to $0^{\circ}, 180^{\circ}$ and $180^{\circ}$ respectively, the centers of gravity become furthest and bending moments become largest. The range of $\theta_{2}$ is $90^{\circ} \sim 180^{\circ}$, which increases or decreases in $10^{\circ}$, as shown in Fig. (2-1).

The second set of working conditions: boom 2 rotates around the hinge point between boom 2 and 3 . According to the existing working conditions, as soon as $\theta_{1}, \theta_{2}$ and $\theta_{4}$ equals to $0^{\circ}, 180^{\circ}$ and $180^{\circ}$ respectively, the centers of gravity become furthest and bending moments become largest. The range of $\theta_{3}$ is $100^{\circ} \sim 360^{\circ}$, which increases or decreases in $20^{\circ}$, as shown in Fig. (2-2).

The third set of working conditions: boom 3 rotates around the hinge point between boom 3 and 4 . According to the existing working conditions, as soon as $\theta_{1}, \theta_{2}$ and $\theta_{3}$ equals to $0^{\circ}, 180^{\circ}$ and $180^{\circ}$ respectively, the centers of gravity become furthest and bending moments become largest. The range of $\theta_{4}$ is $30^{\circ} \sim 240^{\circ}$, which increases or decreases in $10^{\circ}$, as shown in Fig. (2-3).

\section{THE FINITE ELEMENT ANALYSIS ON THE BOOM SYSTEM UNDER MULTIPLE LOAD CASE}

The boom system finite element model. Build the boom system three--dimensional model. Build the 37 meters concrete pump boom system in the software of Pro/Engineer, which is based on the two-dimensional boom system drawn for production. The boom system IS assembled in horizontal posture, then the file format is saved as "IGES" in order to import other analysis software conveniently.

The boom system finite element model is simplified. The three-dimensional boom system model is imported under horizontal posture into the MSC. Patran. The main function of burden distribution tube is to deliver the concrete stents located between burden distribution tube and the booms used for supporting, the one-dimensional rod element is used, with the topology form being BAR2. The hydraulic cylinders located between the adjacent two booms and pin shafts are replaced by one-dimensional rod element [7].

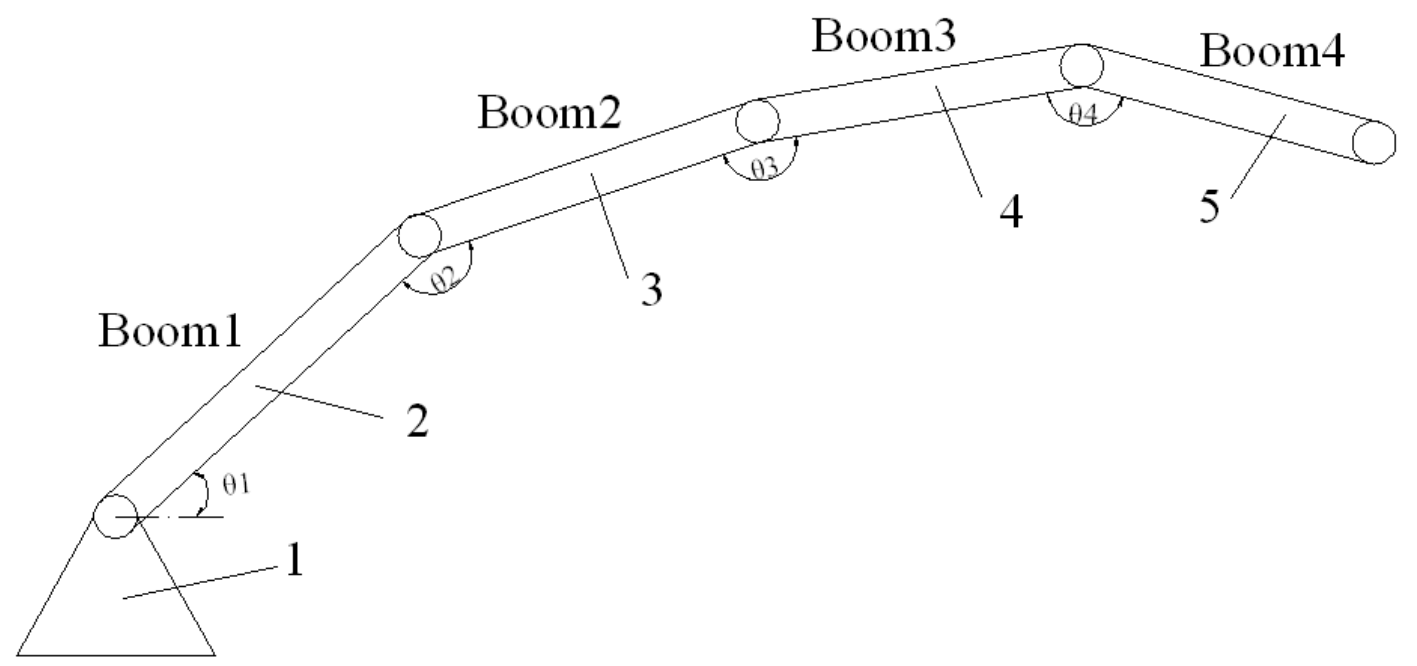

Fig. (1). The boom system frame diagram of $37 \mathrm{~m}$ concrete pump.

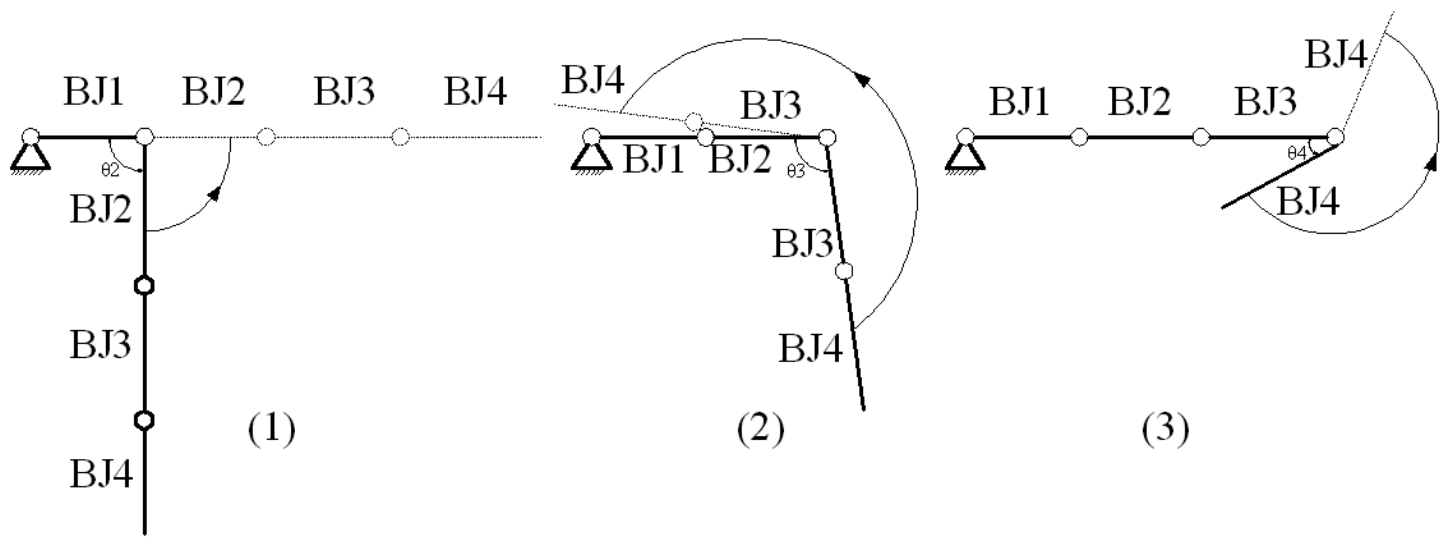

Fig. (2). The three sets of working conditions. 


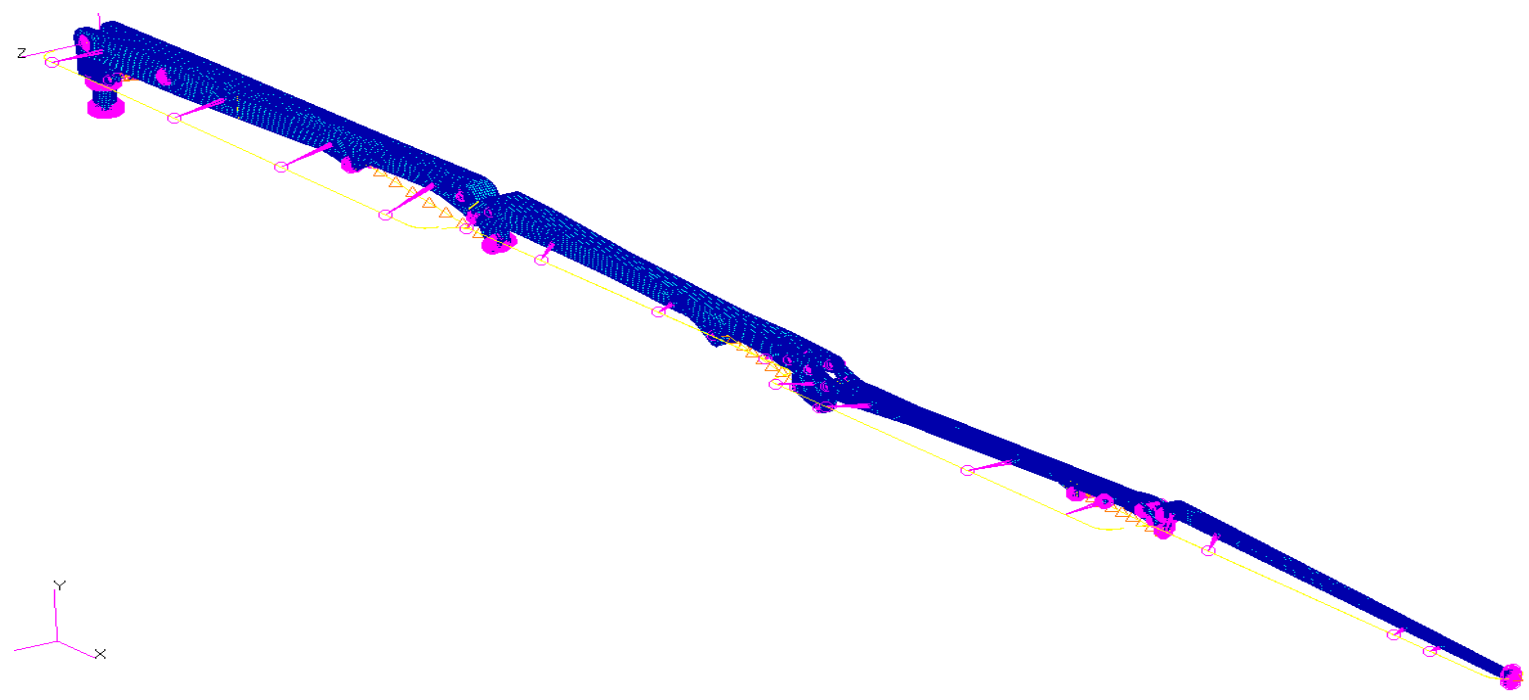

Fig. (3). The finite element model of boom system under level.

The finite element is meshed. The actual structure of the boom system is combined and compared with the three meshing tools IsoMesh, TetMesh and Pver in MSC. Patran, then selects TetMesh as the meshing tool. There are three shapes of elements Bar2, Tria3 and Quad4. The boom system finite element model under horizontal posture after being meshed, is checked and redundant nodes are removed as shown in Fig. (3).

Set the boundary condition and loads: The boundary condition is applied to the chassis of turntable by acting on elements, restricting the translation and rotation of the turntable. When the concrete pump truck is working, there is boom system gravity, the gravity of burden distribution and concrete in it. The force of the transporting hose to the end of boom system and the pressure of wind load on the side of booms are applied on the boom system [8-10].

Apply the gravity of boom system. In MSC. Patran, select "Load/BCs", is selected "Inertial Load" and "Element Uniform" are chosen, and the value of acceleration is input, followed by setting the direction of acceleration.

Apply the gravity of burden distribution and concrete in it. The gravity of burden distribution and concrete in it are taken as a whole, and element density is defined, then the coefficient of dynamic load 1.1 is multiplied.

Apply the force of the transporting hose to the end of boom system. The force of the transporting hose to the end of boom system approximately equals to $1600 \mathrm{~N}$, inputting its value of which, and setting the coefficient of dynamic load as 1.1, the location of the force is then choosen.

Apply the pressure of wind load on the side of booms. The value of wind pressure is set to be $25 \mathrm{pa}$, then the location of wind pressure is chosen, namely one side of each boom.

Define the material properties. In MSC. Patran, the isotropic material is chosen, defining the structure model and inputting the values of elastic modulus and poisson's ratio by means of manual insertion, and then seven kinds of material properties are defined.

Define the element attributes. In MSC. Patran, the element of $1 \mathrm{D}$ beam is selected, followed by the insertion of the name of the material, defining the cross section shape, then choosing the function area. 2D shell created, the material name and thickness are inserted, then the function area is chosen. As the real structure of boom system is very complex, in order to accurately reflect the structure, thirty two kinds of elements properties are established.

Set analysis parameters. The work name is inserted, setting the analysis target as the entire model, and the analysis method is set to "Full Run". The calculator for the corresponding MSC is amended. Nastran version. Linear static analysis as the analysis type is selected, setting the output file format as ".OP2". The boom system is assembled to the corresponding working condition before conducting the analysis.

Read in the analysis results. The reading method is set as "Result Entities", and the result file is selected, then the finite element calculation results are read.

In software MSC. Patran, The analysis parameters are set and the type of analysis is selected. The system then automatically submits the model to MSC. Nastran to conduct static analysis. After the analysis the results are read into MSC. Patran, followed by their viewing.

\section{THE FINITE ELEMENT CALCULATION RESULTS ANALYSIS}

The maximum stresses of small head of boom 1 and big head of boom 2 recieved from the first set of working conditions, the maximum stresses of small head of boom 2 and big head of boom 3 received from the second set of working conditions and the maximum stresses of small head of boom 3 and big head of boom 4 received from the third set of working conditions are inserted in the software MATLAB for numerical analysis. Then changing trends are 
obtained of the maximum stresses subjected by booms with a change of degrees of booms.

It can be seen from Figs. (4-6), when $90^{\circ}<\theta_{2}<120^{\circ}$, the maximum stresses subjected by head of boom 1 and big head of boom 2 are relatively small; when $130^{\circ}<\theta_{3}<170^{\circ}$, the maximum stresses subjected by small head of boom 2 and big head of boom 3 are relatively small; when $50^{\circ}<\theta_{4}<90^{\circ}$, the maximum stresses subjected by small head of boom 3 and big head of boom 4 are relatively small.

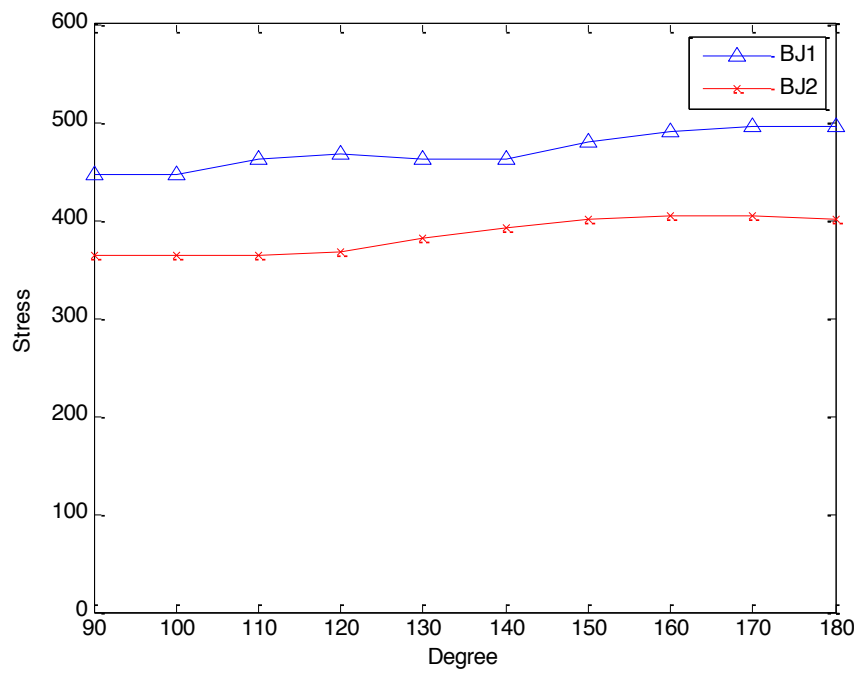

Fig. (4). The changing trends of the maximum stresses subjected by small head of boom 1 and big head of boom 2 with the change of $\theta_{2}$.

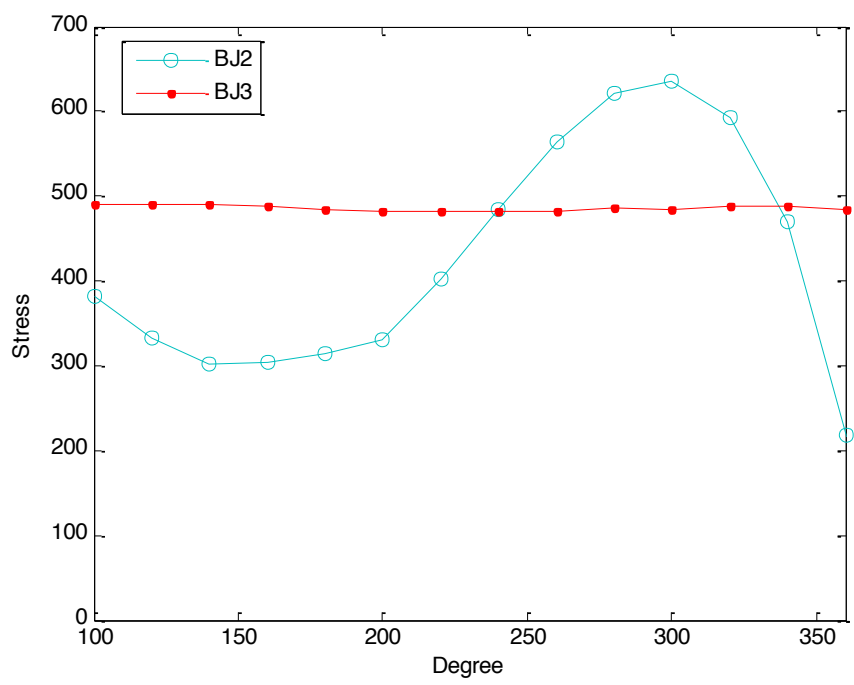

Fig. (5). The changing trends of the maximum stresses subjected by small head of boom 2 and big head of boom 3 with the change of $\theta_{3}$.

When all the four booms are under condition of level, rotating around the turntable, the maximum stresses subjected by big head of boom 1 can be calculated by Eq. (1). In this condition, the boom system can be seen as a cantilever beam of pure bending. The stress and bending moment at the same place are in a directly proportional relationship. When $\theta_{1}$ is in the range of $0^{\circ} \sim 90^{\circ}$, the maximum stresses subjected by big head of boom 1 represents decreasing trend with the increase in $\theta_{1}$, so when $60^{\circ}<\theta_{1}<90^{\circ}$, the maximum stresses subjected by big head are relatively small.

$M_{1}=\sum_{i=1}^{4} \frac{l_{i} G_{i}}{2} \cos \theta_{1}$.

where, $M_{1}$ means the maximum stresses subjected by big head of boom $1 ; l_{i}$ and $G_{i}$ represents the length and weight of the boom I respectively.

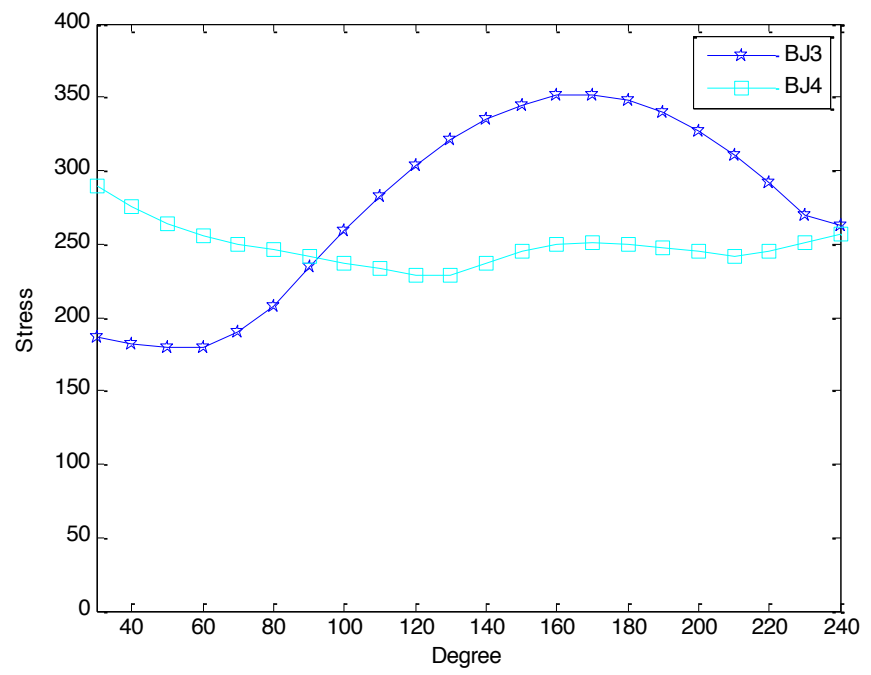

Fig. (6). The changing trends of the maximum stresses subjected by small head of boom 3 and big head of boom 4 with the change of $\theta_{4}$.

Combining the scope of degrees of booms with the concrete pump working and the above analysis results, the concluding condition met by the boom system working in safety is shown by Eq. (2).

$$
\left\{\begin{array}{c}
60^{\circ}<\theta_{1}<90^{\circ} \\
90^{\circ}<\theta_{2}<120^{\circ} \\
130^{\circ}<\theta_{3}<170^{\circ} \\
50^{\circ}<\theta_{4}<90^{\circ}
\end{array}\right.
$$

\section{APPLICATION}

According to the limitation of the length of the boom system, the $37 \mathrm{~m}$ concrete pump is commonly used for the foundation casting and the second floor casting. Through repeated study and communication with the technician in Sany Heavy Industry Company, we learnt that there are four typical working conditions, when concrete pump does foundation casting. The working conditions 1 and 2 are used more often than the other two, because their fatigue life is longer, as shown in Table 1. Degrees of $\theta_{1}$ of the four working conditions are nearly equal, so the stresses of boom system are mainly decided by $\theta_{2}, \theta_{3}$ and $\theta_{4}$.

In all the four working conditions of foundation casting, the $\theta_{2}$ and $\theta_{4}$ of working condition 4, $\theta_{4}$ of working condition 1 and $\theta_{4}$ of working condition 3 , the working condition 2 is the most safe working condition, as it conforms to reality. 
Table 1. The four typical working conditions of boom system of foundation casting.

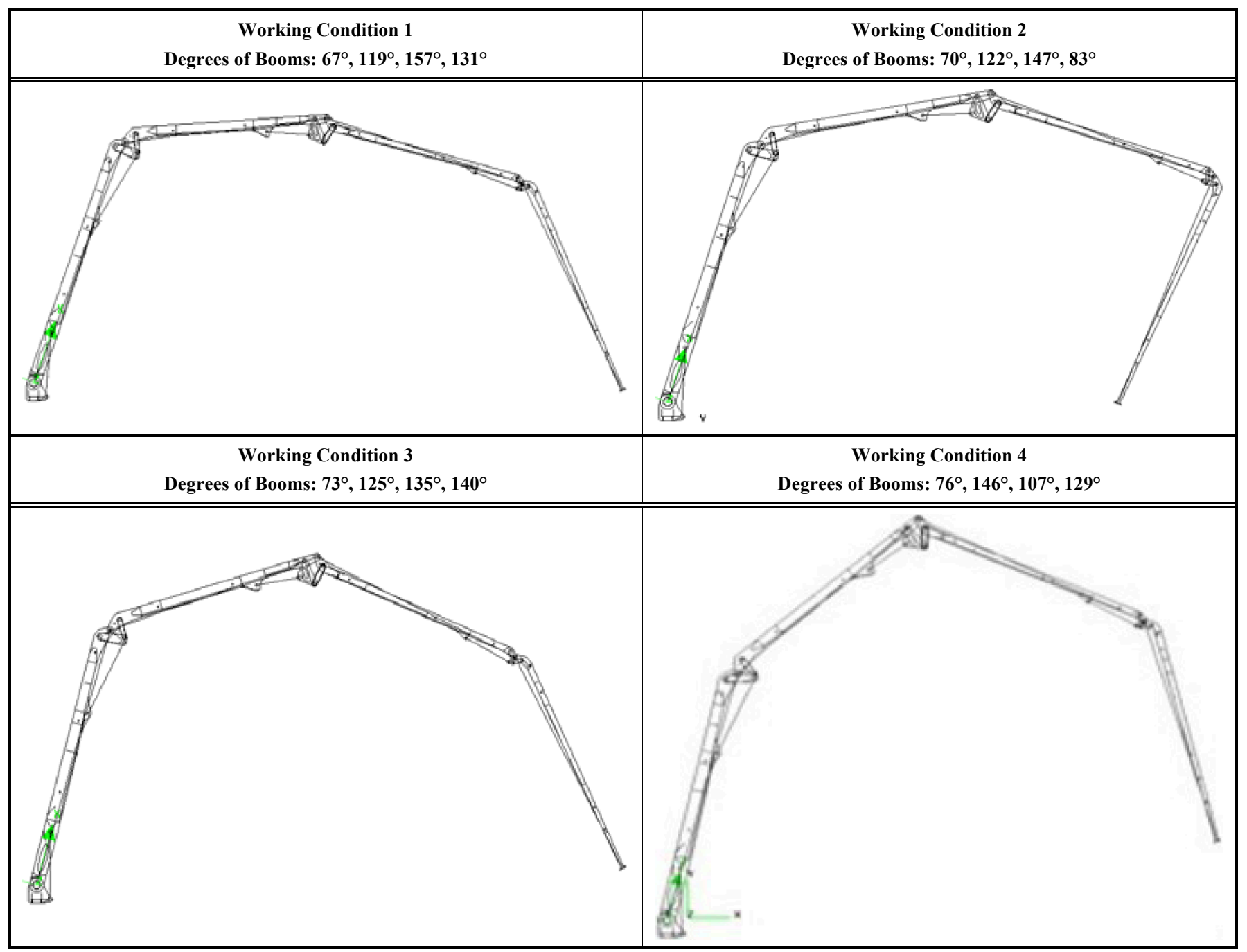

\section{CONCLUSION}

By analyzing the finite element on the boom system under multiple load case, the changing trends are obtained of the maximum stresses subjected by booms with the change of degrees of booms, resulting in the boom system working in safety, and when $\theta_{1}, \theta_{2}, \theta_{3}$ and $\theta_{4}$ equals to $90^{\circ}, 100^{\circ}$, $150^{\circ}$ and $60^{\circ}$ respectively, the maximum stresses subjected by each boom are the smallest.

\section{CONFLICT OF INTEREST}

The authors confirm that this article content has no conflict of interest.

\section{ACKNOWLEDGEMENTS}

This work is financially supported by National Key Technology R\&D Program (2012BAF02B01), the Natural Science Foundation of Hunan Province (14JJ5011) and Aid
Program for Science and Technology Innovative Research Team in Higher Educational Institutions of Hunan Province.

\section{REFERENCES}

[1] S. Zhu, and J. K. Yao, Natural Science. China: China Machine Press, 2009.

[2] W. Zhang, Z. Q. Liu, S. Zhang, and B. S. Xu, "Study and development of green manufacturing and remanufacturing", China Surface Engineering, vol. 19, no. 5, pp. 76-81, 2006.

[3] X. G. Yi, J. T. Li, X. M. Yi, and T. Zhang, "Rotary dynamical property analysis on concrete pump truck booms", Chinese Journal of Construction Machinery, vol. 8, no. 3, pp. 258-263, 2010.

[4] X. J. Lei, Y. H. Liu, and X. Y. Zhang, "Research on fatigue load spectrum for boom frame of concrete pump truck", Construction Machinery and Equipment, vol. 41, pp. 18-21, 2010.

[5] X. J. Tang, Z. Y. Wu, P. K. Shi, and H. M. Li, "Kinematical simulation and control on intelligent booms of concrete pump vehicles", Chinese Journal of Construction Machinery, vol. 6, no. 1, pp. 63-67, 2008

[6] X. Q. Hu, and H. Qin, "Finite element analysis and optimization of arms of the truck mounted concrete pump under complex working 
condition", Construction Machinery Technology \& Management, no. 7, pp. 97-99, 2012.

[7] J. Liu, L. Dai, L. J. Zhao, J. Cai, and J. Zhang, "Modeling and simulation of flexible multi-body dynamics of concrete pump truck arm", Chinese Journal of Mechanical Engineering, vol. 43, no. 11, pp. 131-135, 2007.
[8] X. H. Zhu, X. Gao, and Y. X. Wang, "Finite element analysis on the boom system of a concrete pump mounted on truck", Machine Tool \& Hydraulics, vol. 40, no. 5, pp. 138-142, 2012.

[9] W. X. Ma, Vehicles for Special Services. China: Chemical Industry Press, 2006.

[10] R. Q. Yin, "Overall designing for truck-mounted concrete pump with $48 \mathrm{~m}$ boom bracket", Construction Machinery Technology \& Management, no. 1, pp. 87-90, 2006.

(C) Yue et al.; Licensee Bentham Open.

This is an open access article licensed under the terms of the Creative Commons Attribution Non-Commercial License (http://creativecommons.org/licenses/ by-nc/3.0/) which permits unrestricted, non-commercial use, distribution and reproduction in any medium, provided the work is properly cited. 